\title{
Human arthroplasty derived macrophages differentiate into osteoclastic bone resorbing cells
}

Afsaneh Sabokbar, Yosuke Fujikawa, Susan Neale, David W Murray, Nicholas A Athanasou

\begin{abstract}
Objective-In aseptic loosening, a heavy macrophage response to biomaterial wear particles is commonly found in arthroplasty tissues. The aim of this study was to discover if these cells contribute to the bone resorption of aseptic loosening by differentiating into osteoclasts.
\end{abstract}

Methods-Macrophages were isolated from the pseudocapsule and pseudomembrane of loose cemented and uncemented hip arthroplasties at the time of revision surgery and then co-cultured on glass coverslips and dentine slices with UMR 106 rat osteoblast-like cells, both in the presence and absence of 1,25 dihydroxyvitamin $D_{3}\left[1,25(\mathrm{OH})_{2} D_{3}\right]$. Macrophages isolated from the synovial membrane of patients with osteoarthritis (OA) undergoing hip replacements were similarly studied as a control group.

Results-After 24 hours incubation, most cells isolated from the above periprosthetic tissues strongly expressed macrophage (CD11b, CD14) but not osteoclast markers. However, after 14 days incubation, numerous multinucleated cells showing the phenotypic features of osteoclasts (that is, positive for tartrate resistant acid phosphatase, the vitronectin receptor, and capable of extensive lacunar resorption) formed in co-cultures of arthroplasty derived macrophages and UMR 106 cells, in the presence of $1,25(\mathrm{OH})_{2} \mathrm{D}_{3}$. The addition of an antibody to macrophage colony stimulating factor (M-CSF) considerably reduced macrophage-osteoclast differentiation and hence the lacunar resorption seen in these co-cultures. In contrast, $O A$ synovial macrophage/UMR 106 co-cultures showed little or no evidence of macrophageosteoclast differentiation and this was only seen when human M-CSF was added to the co-cultures.

Conclusion-This is the first report showing that human macrophages isolated directly from periprosthetic tissues surrounding loosened implants can differentiate into multinucleated cells showing all the functional and cytochemical characteristics of osteoclasts. In contrast with other macrophage populations, exogenous M-CSF is not required for this to occur. In the context of the heavy macrophage response to wear particles in periprosthetic tissues macrophage-osteoclast differentiation may represent an important cellular mechanism whereby osteolysis is effected in aseptic loosening.

(Ann Rheum Dis 1997;56:414-420)

Aseptic loosening is the commonest cause of late failure of cemented and uncemented joint replacements. It is associated with the presence of a prominent foreign body macrophage response to polymeric and metallic wear particles in the pseudocapsule and pseudomembrane surrounding the implant. ${ }^{1-3}$ Considerable periprosthetic bone resorption may be found in the vicinity of this macrophage-rich pseudomembrane. ${ }^{45}$ The cellular mechanisms underlying this pathological bone resorption and the manner in which the heavy foreign body macrophage infiltrate in periprosthetic tissues contributes to this osteolysis remain uncertain.

It is well recognised that macrophages that have phagocytosed polymeric or metallic wear particles produce humoral factors (for example, cytokines/growth factors and prostaglandins) that are known to activate osteoblasts to stimulate osteoclastic bone resorption. ${ }^{6-10}$ However, another means whereby macrophages could contribute directly to the osteolysis of aseptic loosening is through differentiation of these cells into bone resorbing osteoclasts. Murine monocytes and tissue macrophages ${ }^{11-13}$ as well as circulating human monocytes ${ }^{14}$ have been shown to be capable of differentiating in vitro into cells that show all the cytochemical and functional features of osteoclasts. The two absolute cellular and hormonal factors required for this to occur are co-culture with osteoblastic or other specific bone derived stromal cells and the presence of 1,25 dihydroxyvitamin $\mathrm{D}_{3}$ $\left[1,25(\mathrm{OH})_{2} \mathrm{D}_{3}\right]$. Quinn et al ${ }^{11}$ showed that under these cellular and hormonal conditions mouse inflammatory foreign body macrophages, derived from granulomas formed in response to subcutaneously implanted polymethylmethacrylate (PMMA) particles, are capable of differentiating into osteoclastic cells that produce extensive lacunar resorption; the latter is a unique functional characteristic of osteoclastic cells. ${ }^{15}{ }^{16}$ Pandey et $a l^{17}$ extended these studies, showing that inflammatory macrophages responding to particles of all types of polymeric and metallic biomaterials commonly used in arthroplasty surgery are similarly capable of differentiating into osteoclastic lacunar bone resorbing cells. 
These animal studies indicated that biomaterial wear particle associated macrophages, which form the major component of the inflammatory response in periprosthetic tissues, may contribute to the osteolysis of aseptic loosening by differentiating into mature functional osteoclasts. In this study our aim has been to determine directly whether human wear particle associated macrophages present in the periprosthetic tissues around loosened implants are capable of differentiation into osteoclastic bone resorbing cells, and the cellular and humoral conditions required for this to occur. As controls we have determined whether macrophages isolated from the synovial membrane of patients suffering from osteoarthritis (OA) are similarly capable of osteoclast differentiation. In this study we have also characterised the role of macrophage colony stimulating factor (M-CSF), which is known to be an essential cofactor for both murine and human osteoclast differentiation, ${ }^{14}{ }^{18}$ in arthroplasty derived macrophageosteoclast differentiation.

\section{Methods}

For all incubations RPMI-1640 (Gibco, UK) was supplemented with $100 \mathrm{IU} / \mathrm{ml}$ penicillin, $10 \mu \mathrm{g} / \mathrm{ml}$ streptomycin, $10 \mathrm{mM}$ l-glutamine (Gibco, UK), and 10\% fetal calf serum (FCS) (Gibco, UK) (RPMI/FCS). 1,25 dihydroxyvitamin $\mathrm{D}_{3}\left[1,25(\mathrm{OH})_{2} \mathrm{D}_{3}\right]$ (Solvay Duphar, the Netherlands) was dissolved in absolute alcohol and stored at $-20^{\circ} \mathrm{C}$. The cloned hormone responsive rat osteosarcoma cell line UMR 106, which has an osteoblast-like phenotype, ${ }^{19}$ was kindly provided by Professor T J Martin (Melbourne, Australia). Collagenase type I and $0.25 \%$ trypsin solution were purchased from Sigma Chemicals (UK). All incubations were carried out at $37^{\circ} \mathrm{C}$ in $5 \%$ $\mathrm{CO}_{2}$.

ISOLATION OF CELLS FROM THE ARTHROPLASTY PSEUDOMEMBRANE AND OA SYNOVIAL MEMBRANE Specimens of the hip pseudocapsule and femoral and acetabular pseudomembrane were obtained from seven patients undergoing revision arthroplasty for aseptic loosening of the hip. Table 1 gives the clinical details for each patient. As a control group, synovial tissue was obtained from four patients (three female, one male with average age of 65 years) undergoing total hip replacements for OA. Tissue specimens were washed thoroughly with phosphate buffered saline (PBS) before being cut into small fragments and digested in RPMI-1640 containing $1 \mathrm{mg} / \mathrm{ml}$ collagenase

Table 1 Clinical details of patients from whom revision arthroplasty specimens were obtained

\begin{tabular}{lllll}
\hline Case no & Age $(y)$ & Sex & Implant biomaterial & Duration of implant $(y)$ \\
\hline 1 & 76 & M & SS, UHMWPE, PMMA & 3 \\
2 & 52 & M & CoCr, UHMWPE, PMMA & 8 \\
3 & 74 & F & SS, UHMWPE, PMMA & 16 \\
4 & 81 & M & SS, UHMWPE, PMMA & 12 \\
5 & 69 & M & Ti, CoCr, ceramic, UHMWPE & 4 \\
6 & 50 & F & Ti, ceramic, UHMWPE & 3 \\
7 & 75 & M & SS, UHMWPE, PMMA & 8 \\
\hline \multicolumn{7}{l}{ SS = stainless steel, UHMWPE = ultra high molecular weight polyethylene, Ti = titanium alloy, }
\end{tabular}

$\mathrm{CoCr}=$ cobalt-chrome, $\mathrm{PMMA}=$ polymethylmethacrylate. type I for 30 minutes at $37^{\circ} \mathrm{C}$; this was followed by a further one hour incubation in $0.25 \%$ trypsin. The digested tissue was filtered with a $70 \mu \mathrm{m}$ cell strainer (Falcon, UK) and the filtrate centrifuged at $800 \mathrm{~g}$ for 10 minutes. The cell pellet was resuspended in RPMI/FCS and the number of leucocytes counted in a haemocytometer after lysis of red blood cells using a $5 \%(\mathrm{v} / \mathrm{v})$ acetic acid solution.

PREPARATION OF CO-CULTURES ON GLASS COVERSLIPS AND DENTINE SLICES

Twenty four hours before the isolation of cells from arthroplasty or OA tissues, $2 \times 10^{4} \mathrm{UMR}$ 106 cells were added to 96 well tissue culture plates containing dentine slices $(4 \mathrm{~mm})$ and coverslips $(6 \mathrm{~mm})$. The cell suspension obtained from surgical specimens was added to each well $\left(1 \times 10^{5}\right.$ cells/well $)$ and incubated for two hours, after which time all dentine slices and coverslips were removed from the wells, washed vigorously in RPMI/FCS to remove non-adherent cells, and then placed in $16 \mathrm{~mm}$ wells of a 24 well tissue culture plate containing $1 \mathrm{ml}$ of RPMI/FCS supplemented with $1,25(\mathrm{OH})_{2} \mathrm{D}_{3} \quad\left(10^{-7} \mathrm{M}\right)$ and hydrocortisone $\left(10^{-6} \mathrm{M}\right)$. These co-cultures were incubated for one, seven, and 14 days and the culture medium containing these factors was replenished every three days.

To determine the cellular and humoral requirements for osteoclast generation, the OA and arthroplasty derived macrophages were also cultured in: (a) the absence of UMR 106 cells; (b) the absence of $1,25(\mathrm{OH})_{2} \mathrm{D}_{3}$; (c) the presence of recombinant M-CSF $(25 \mathrm{ng} / \mathrm{ml}$, for OA specimens only); (d) the presence of a mouse antihuman M-CSF neutralising antibody $(10 \mu \mathrm{g} / \mathrm{ml}$, for arthroplasty specimens only).

HISTOCHEMICAL AND IMMUNOHISTOCHEMICAL CHARACTERISATION OF CULTURED CELLS

After 24 hours and seven days incubation, all cell cultures were characterised histochemically for the expression of tartrate resistant acid phosphatase (TRAP).$^{20}$ Using a commercially available kit (Sigma, UK), cell preparations were fixed in citrate/acetone solution and stained for acid phosphatase, using naphthol AS-BI phosphate as a substrate, in the presence or absence of $1.0 \mathrm{M}$ tartrate; the product was reacted with Fast Garnet GBC salt. They were then counterstained with haematoxylin stain as recommended by the suppliers.

Cell preparations on coverslips were also stained immunohistochemically, using an indirect immunoperoxidase technique, with the monoclonal antibody 23C6 (a gift of Professor M A Horton, London): this is directed against CD51, the vitronectin receptor (VNR), a highly osteoclast associated antigen. ${ }^{21}$ In addition, cell preparations were similarly stained with monoclonal antibodies TNG6-5 and GRS1, directed against CD11b and CD14 respectively, macrophage associated antigens, which are known not to be expressed by osteoclasts. ${ }^{22}$ All the immunohistochemical preparations were nuclear counterstained routinely 
with haematoxylin. All monoclonal antibodies were obtained from the 5th International Workshop On Human Leucocyte Differentiation Antigens. ${ }^{23}$

FUNCTIONAL EVIDENCE OF OSTEOCLAST DIFFERENTIATION: DETECTION OF LACUNAR RESORPTION USING SCANNING ELECTRON MICROSCOPY (SEM)

Bone resorption studies were carried out using dentine slices as these provide a smooth surfaced mineralised substrate for the assessment of lacunar resorption. ${ }^{15}$ After one and 14 days, dentine slices were removed, rinsed in PBS, and placed in $0.25 \%$ trypsin for 15 minutes; they were then washed vigorously in distilled water and left overnight in $0.25 \mathrm{M}$ ammonium hydroxide. In this way all cells are completely removed from the dentine slice, permitting examination of the dentine surface for evidence of lacunar resorption. The slices were then dehydrated through a graded ethanol series, air dried, and mounted on SEM stubs (Agar Scientific Laboratories, UK). They were then gold sputtered and examined in a Phillips SEM 505 scanning electron microscope. The extent of lacunar resorption was determined by counting the number of resorption pits on three dentine slices. The mean number of resorption pits on each dentine slice was also calculated.

\section{STATISTICAL ANALYSIS}

Results are expressed as the number of lacunar resorption pits per dentine slice. Where appropriate, the average number of resorption pits for $\mathrm{M}-\mathrm{CSF}$ and anti M-CSF treatment was compared using a paired Student's $t$ test $(\mathrm{n}=3)$.

\section{Results}

HISTOLOGY OF ARTHROPLASTY DERIVED AND OA SYNOVIAL TISSUES

Both the pseudocapsule and pseudomembrane specimens derived from patients undergoing revision arthroplasties contained a heavy macrophage and macrophage polykaryon reaction to polymeric and metallic biomaterial wear particles. Some specimens also contained tiny fragments of bone or focal areas of calcification within these periprosthetic tissues. Specimens of the OA synovial membrane generally showed patchy intimal thickening and subintimal fibrosis and oedema. In most cases a light or moderately heavy macrophage infiltrate was noted; in some cases small bone fragments derived from the eroded articular surface were noted in the synovial membrane.

HISTOCHEMICAL AND IMMUNOHISTOCHEMICAL CHARACTERISATION OF CELLS ISOLATED FROM ARTHROPLASTY AND OA SYNOVIAL TISSUES All adherent cells isolated from the arthroplasty pseudocapsule and pseudomembrane, incubated alone for 24 hours on glass coverslips, showed strong expression of CD $11 \mathrm{~b}$ and CD14, (fig 1A) macrophage cell surface antigens that are known not to be present on osteoclasts. ${ }^{23}$ These 24 hour cultures were also largely negative for the osteoclast markers, TRAP and VNR (fig 1B). In two cases (case 1 and case 2), 24 hour cultures of cells derived from the arthroplasty pseudomembrane did show occasional TRAP and VNR positive multinucleated cells (less than four per coverslip). For all cases, a similar pattern of expression of macrophage and osteoclast markers was noted when arthroplasty derived cells were co-cultured with UMR 106 cells on glass coverslips for 24 hours in the presence or the absence of $1,25(\mathrm{OH})_{2} \mathrm{D}_{3}$ and $\mathrm{M}-\mathrm{CSF}$.

After seven days incubation, co-cultures of arthroplasty derived macrophages and UMR 106 cells, incubated in the presence of $1,25(\mathrm{OH})_{2} \mathrm{D}_{3}$, contained TRAP and VNR positive mononuclear and multinucleated cells. TRAP positive cells were particularly numerous and included not only scattered mononuclear and multinucleated TRAP positive cells but also small and large clusters of cells showing TRAP positivity (fig $2 A$ ). VNR positive cells were much less numerous, being evident as isolated multinucleated cells; they were most easily seen where part of the covering layer of UMR 106 cells had become detached from the surface of the coverslip (fig 2B). In the absence of UMR 106 cells, scattered TRAP positive mononuclear and multinucleated cells were seen in cultures, both in the presence and absence of $1,25(\mathrm{OH})_{2} \mathrm{D}_{3}$, but VNR positive cells were not noted except in specimens derived from cases 1 and 2 . Numerous CD11b and CD14 positive cells were seen in all the seven day cultures incubated both in the presence and absence of UMR 106 cells.

In 24 hour cultures on glass coverslips of cells isolated from the OA synovium, there was also strong expression of macrophage markers
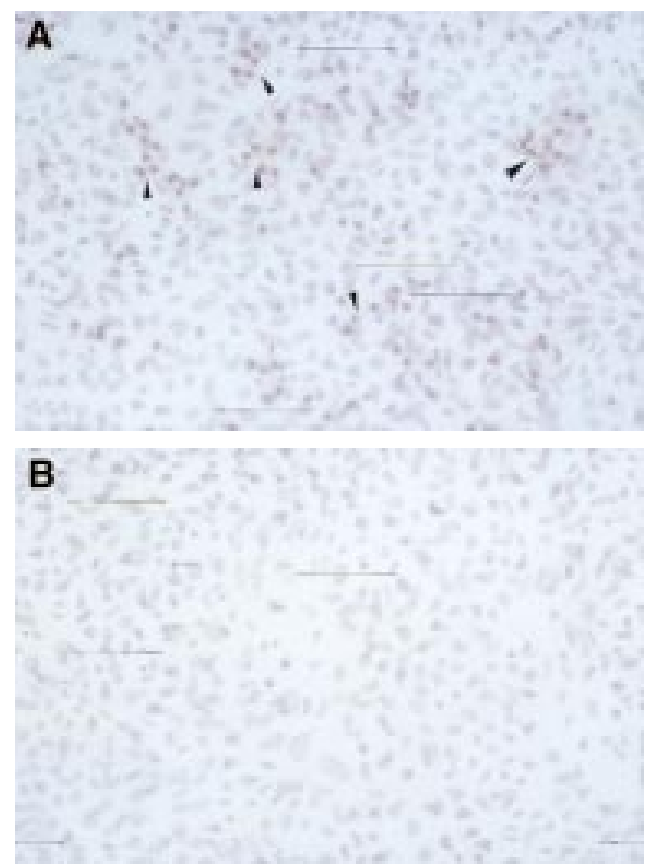

Figure 1 Twenty four hour culture of arthroplasty derived macrophages incubated with UMR 106 cells (in the presence of $1,25(\mathrm{OH}) \mathrm{D}_{\mathrm{J}}$ ) stained by an indirect immunoperoxidase technique with monoclonal antibodies. (A) GRS 1 (anti-CD14) and (B) 23C6 (antiVNR), showing reaction for CD14 (arrows) but not VNR on isolated cells. This indicates that these cells express a monocyte/macrophage but not osteoclast immunophenotype. (Original magnification $\times 200$ ). 

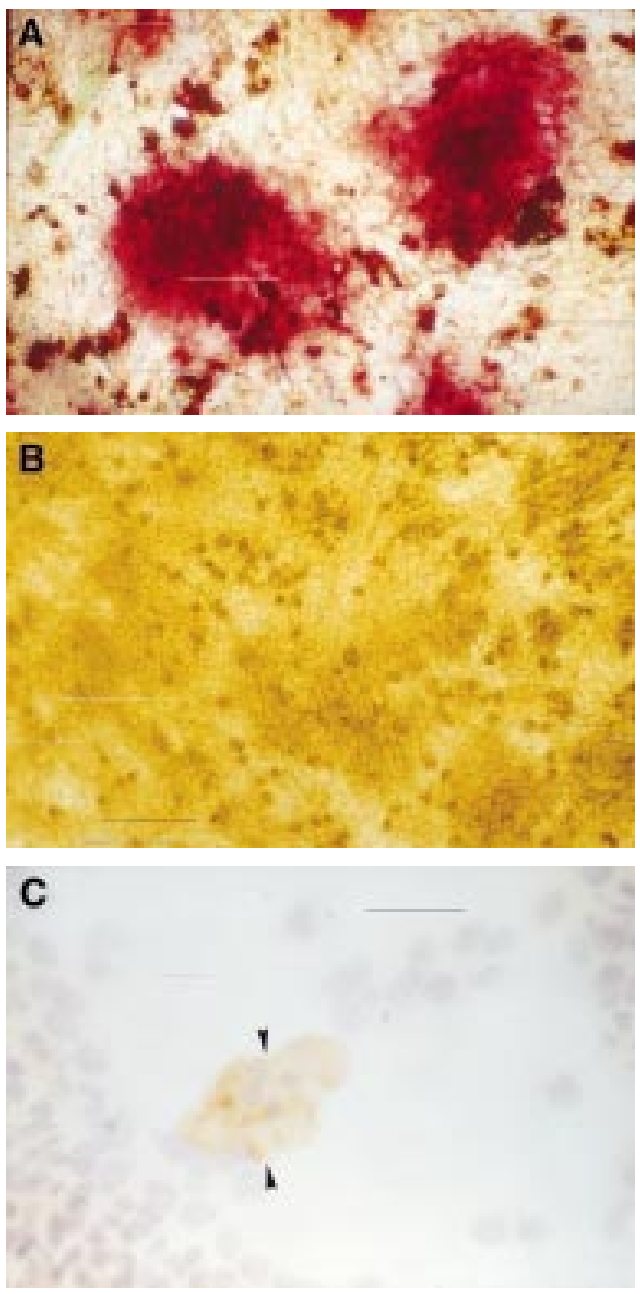

Figure 2 Seven day culture of arthroplasty derived macrophages incubated with UMR 106 cells showing: $(A)$ clusters of TRAP positive cells in the presence of $1,25(\mathrm{OH})_{2} D_{3}$. (Original magnification $\left.\times 200\right)$. (B) negative control for the TRAP staining (that is, in the absence of $1,25(\mathrm{OH})_{2} D_{3}$. (Original magnification $\times 200$ ). (C) A VNR positive multinucleated cell (arrow heads). (Original magnification $\times 400$ ).

(CD11b and CD14). In addition, occasional TRAP and VNR positive multinucleated cells were noted. In 24 hour co-cultures of OA synovial macrophages and UMR 106 cells, a similar pattern of expression of macrophage and osteoclast markers was seen, both in the presence and absence of $1,25(\mathrm{OH})_{2} \mathrm{D}_{3}$ and $M-C S F$. The number of TRAP and VNR positive cells in seven days co-cultures of OA synovial macrophages and UMR 106 cells was unchanged in the presence of $1,25(\mathrm{OH})_{2} \mathrm{D}_{3}$. However, in the presence of recombinant human $\mathrm{M}$-CSF (and 1,25(OH $\left.)_{2} \mathrm{D}_{3}\right)$, an increase in the number of cells expressing these osteoclast markers was observed.

FUNCTIONAL CHARACTERISATION OF CELLS CULTURED FROM ARTHROPLASTY AND OA SYNOVIAL TISSUES: HUMORAL REQUIREMENTS FOR HUMAN ARTHROPLASTY DERIVED MACROPHAGE-OSTEOCLAST DIFFERENTIATION Both in the presence and absence of UMR 106 cells and $1,25(\mathrm{OH})_{2} \mathrm{D}_{3}$, lacunar resorption was not detected in 24 hour cultures of arthroplasty derived macrophages on dentine slices in six of seven cases studied. The one case (case 2) that showed evidence of resorption pit formation had a few small pits on two of three dentine slices examined after 24 hours in culture (table 2).

In 14 day co-cultures of arthroplasty derived macrophages and UMR 106 cells, in the presence of $1,25(\mathrm{OH})_{2} \mathrm{D}_{3}$, extensive lacunar pit formation was evident on all dentine slices of the seven cases studied (table 2 and fig 3 ). Under these conditions the mean number of resorption pits in each case ranged from 50 to 120 on each dentine slice; on some slices more than 140 resorption pits were seen. Most resorption pits were large and composed of multiple areas of lacunar excavation of the dentine surface.

Lacunar resorption was not seen when arthroplasty derived macrophages were cultured in the absence of UMR 106 cells (with added $\left.1,25(\mathrm{OH})_{2} \mathrm{D} 3\right)$ ) in five of seven cases studied. In case 1 , one small resorption pit was seen on one of three dentine slices examined and in case 2, a few (less than 10) small resorption pits were found on all three dentine slices after 14 days incubation (table 2). In all cases studied, no pits were formed in the absence of $1,25(\mathrm{OH})_{2} \mathrm{D}_{3}$.

In OA synovial macrophage/UMR-106 co-cultures, after one and 14 days incubation, lacunar resorption was seen in three of four cases. The number of resorption pits formed on dentine slices in these co-cultures ranged from 1 to 44 per dentine slice (table 3 ). The extent of lacunar bone resorption seemed to be unaffected by the presence or absence of either UMR 106 cells or $1,25(\mathrm{OH})_{2} \mathrm{D}_{3}$ in these co-cultures. However, after the addition of recombinant human M-CSF (25 ng/ml), there was a significant increase in the number of lacunar resorption pits formed in all OA synovial macrophage-UMR 106 co-cultures in the presence of $1,25(\mathrm{OH})_{2} \mathrm{D}_{3}$ (table 3). These results suggested that $\mathrm{M}$-CSF plays an important part in human macrophage-osteoclast differentiation. Therefore, to determine further whether M-CSF also plays a part in osteoclast

Table 2 Number of lacunar resorption pits formed on dentine slices after one and 14 day incubation (with added $\left.1,25(\mathrm{OH})_{2} D_{3}\right)$ of arthroplasty derived macrophages in the presence or the absence of UMR 106 cells. The mean number of resorption pits for each case is shown in parentheses

\begin{tabular}{lllll}
\hline Revision case no & At day 1 No UMR 106 & At day 1 + UMR 106 & At day 14 No UMR 106 & At day 14+ UMR 106 \\
\hline 1 & - & - & $1,0,0(0.3)$ & $87,104,35(75)$ \\
2 & $1,4,0(1.6)$ & - & $5,7,10(7.3)$ & $56,22,71(50)$ \\
3 & - & - & - & $120,141,98(120)$ \\
4 & - & - & - & $100,108,129(112)$ \\
5 & - & - & - & $75,84,112(90)$ \\
6 & - & - & - & $140,58,95(98)$ \\
7 & - & - & $80,109,95(95)$ \\
\hline
\end{tabular}

$-=$ No lacunar pits on all dentine slices. 
formation by cells derived from arthroplasty tissues, a neutralising antibody to human M-CSF $(10 \mu \mathrm{g} / \mathrm{ml})$ was added to cultures of macrophages isolated from cases 6 and 7. In both these cases there was pronounced inhibition of TRAP and VNR expression (at day 7) (data not shown) and lacunar resorption (at day 14) (fig 4).

\section{Discussion}

Wear particles derived from implant biomaterials induce a pronounced foreign body macrophage response in both the pseudocapsule and pseudomembrane surrounding arthroplasty components. ${ }^{2425}$ The clinical severity and rapidity of onset of aseptic loosening can be correlated with both the amount of wear particles and the extent of the macrophage response in these periprosthetic tissues. ${ }^{26-28}$ In this study we have shown that this wear particle associated macrophage infiltrate contains cells that are capable of osteoclast differentiation. Cultures of arthroplasty derived macrophages required the presence of osteoblastic cells and $1,25(\mathrm{OH})_{2} \mathrm{D}_{3}$ for osteoclast differentiation, but did not require

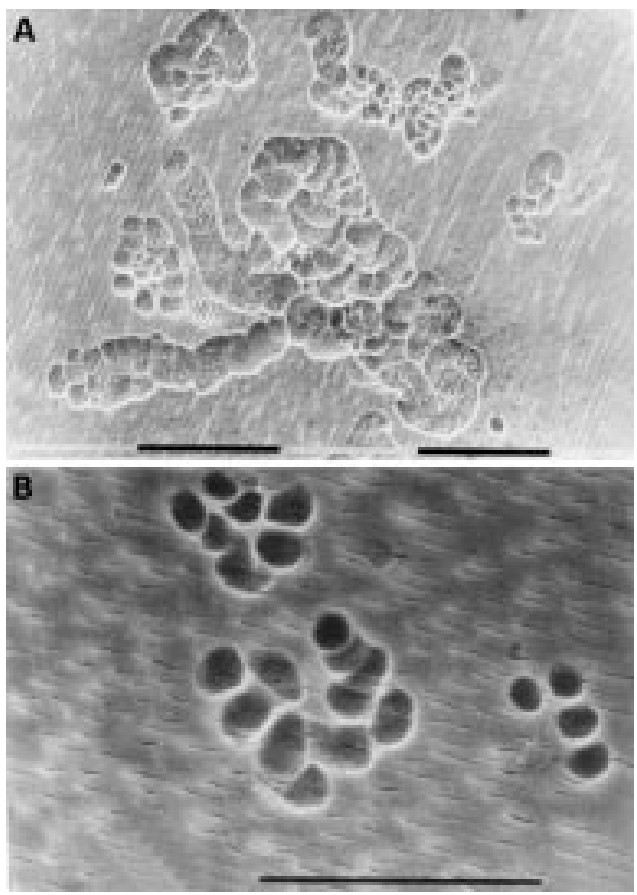

Figure 3 (A) Fourteen day culture of arthroplasty derived macrophages incubated with UMR 106 cells on dentine slices. The cells have been removed to reveal evidence of lacunar resorption with the formation of numerous well defined resorption pits. (Black bar $=100 \mu \mathrm{m}$ ).

(B) $A$ high power view of individual resorption pits. (Black bar $=100 \mu \mathrm{m})$.

Table 3 Number of lacunar resorption pits formed on dentine slices after 14 day incubation in $O A$ derived macrophage/UMR 106 co-cultures (with added 1,25(OH) ${ }_{2} D_{3}$ ) in the presence or the absence of recombinant human M-CSF. The mean number of resorption pits for each case is shown in parentheses and the p value for the Student's $t$ test is also given

\begin{tabular}{llll}
\hline OA case no & $\begin{array}{l}\text { No of lacunar pits } \\
\text { (No } M \text {-CSF) }\end{array}$ & $\begin{array}{l}\text { No of lacunar pits } \\
\text { (Plus } M \text {-CSF) }\end{array}$ & p Value \\
\hline 1 & $0,0,0(0)$ & $108,78,95(94)$ & 0.00042 \\
2 & $24,15,44(28)$ & $49,68,92(70)$ & 0.0498 \\
3 & $17,12,13(14)$ & $48,120,123(97)$ & 0.027 \\
4 & $10,2,1(4)$ & $55,76,23(51)$ & 0.039 \\
\hline
\end{tabular}

the addition of M-CSF; the latter is in contrast with osteoclast differentiation by cultures of human monocytes and synovial macrophages. ${ }^{1429}$

A pronounced increase in the expression of cytochemical and functional osteoclast phenotypic features was noted when arthroplasty derived macrophages were co-cultured with UMR 106 cells in the presence of $1,25(\mathrm{OH})_{2} \mathrm{D}_{3}$. Under these culture conditions, numerous TRAP and VNR positive multinucleated cells formed on glass coverslips and extensive lacunar resorption was seen on dentine slices. The average lacunar resorption noted in each case was in the range of 50 to 120 resorption pits per dentine slice with each pit being composed of numerous individual lacunar excavations; this represents lacunar resorption of approximately $10 \%$ of the surface area of the dentine slice. In the absence of $1,25(\mathrm{OH})_{2} \mathrm{D}_{3}$ or UMR 106 cells, there was little expression of TRAP or VNR, and little or no evidence of resorption pit formation. Although a few small isolated resorption pits were noted in the absence of UMR 106 cells and $1,25(\mathrm{OH})_{2} \mathrm{D}_{3}$ in 24 hour and 14 day cultures of macrophages isolated from the arthroplasty pseudomembrane of two cases, this was not an unexpected finding as multinucleated cells expressing an osteoclast-like phenotype and a small amount of lacunar resorption by osteoclasts isolated from periprosthetic tissues has previously been noted. ${ }^{30-32}$ The few resorption pits formed in these two cases were most probably produced by osteoclasts associated with bone particles embedded in the pseudomembrane; this is supported by the finding of a few TRAP and VNR positive multinucleated cells in 24 hour cultures of the cell suspension isolated from these pseudomembrane specimens. In control cultures, cells isolated from the OA synovium, which also typically contained small bone fragments derived from the eroded articular surface, similarly showed isolated TRAP and VNR positive cells and formation of a few resorption pits in both 24 hour and seven day culture.

Our results show that the inflammatory foreign body macrophage infiltrate in periprosthetic tissues surrounding loose arthroplasty components contains mononuclear osteoclast precursors, and that these cells express the phenotypic characteristics of macrophages and not osteoclasts. Post-mitotic osteoclast precursors of marrow origin have been shown to lose and to acquire macrophage and osteoclast markers respectively in the process of osteoclast differentiation. ${ }^{33}$ This is paralleled by the change in the cytochemical and functional phenotype that occurs in our co-culture system where isolated arthroplasty derived cells expressed almost exclusively macrophage and not osteoclast characteristics but became TRAP and VNR positive and acquired the ability to carry out extensive lacunar resorption after long term co-culture with UMR 106 cells in the presence of $1,25(\mathrm{OH})_{2} \mathrm{D}_{3}$. 


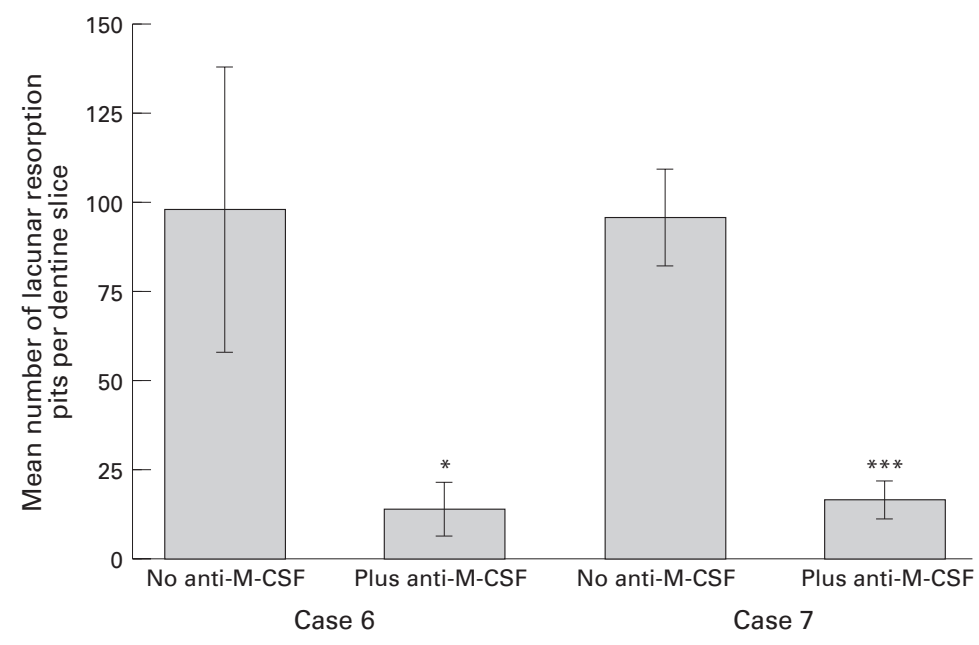

Figure 4 Effect of neutralising anti-M-CSF antibody on the mean number of lacunar pits formed on dentine slices from co-cultures of arthroplasty derived macrophages from case numbers 6 and 7. Results are expressed as mean (SD). Levels of significance using Student's paired t test: $\left(^{\star}\right) ; p=0.024$ and $\left({ }^{\star \star \star}\right) ; p=0.00092$.

The presence of osteoblast-like cells and $1,25(\mathrm{OH})_{2} \mathrm{D}_{3}$ was found to be necessary for osteoclast differentiation by human arthroplasty derived macrophages to occur in vitro. Animal studies using haematopoietic cells and mononuclear phagocytes as osteoclast precursors have also shown the importance of these factors in osteoclast differentiation. ${ }^{131833-35}$ Using mouse haematopoietic cells, it has been shown that osteoclast formation proceeds in two phases: an initial phase of proliferation of osteoclast precursors, and the second phase in which these cells mature into osteoclasts ${ }^{18}$; both $\mathrm{M}-\mathrm{CSF}$ and $1,25(\mathrm{OH})_{2} \mathrm{D}_{3}$ were found to be essential for osteoclast formation under these conditions. Studies of the disease osteopetrosis in $o p / o p$ mice, in which there is a failure of osteoclast formation, have also shown that M-CSF is an important factor in osteoclast generation. ${ }^{3637}$ Fujikawa et a ${ }^{1429}$ have also recently found that M-CSF is an absolute requirement for osteoclast formation from
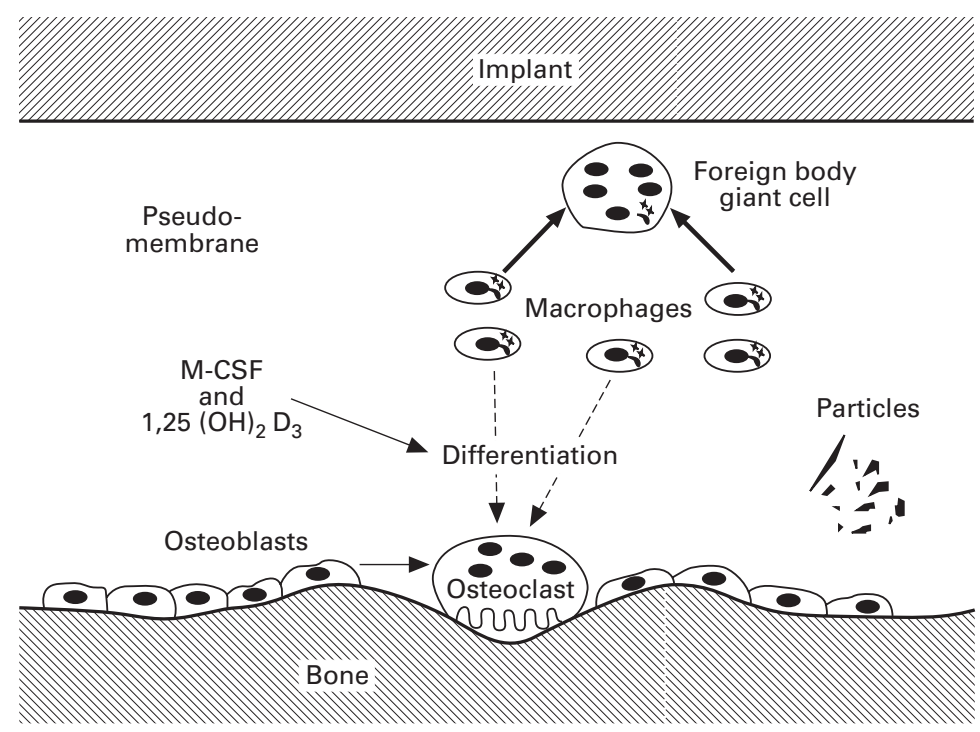

Figure 5 Proposed cellular and humoral mechanism whereby human wear particle induced foreign body macrophages in the periprosthetic tissues differentiate into osteoclastic bone resorbing cells. human monocytes and rheumatoid synovial macrophages in vitro. In this study, we have also shown that the addition of M-CSF to OA synovial macrophage/UMR 106 co-cultures considerably increases the extent of macrophage-osteoclast differentiation. It is therefore notable that human osteoclast formation from arthroplasty derived macrophages did not require the addition of M-CSF. One possible explanation for this is that any $M-C S F$ required for macrophage-osteoclast differentiation is produced endogenously by one of the cell types present in the periprosthetic tissues. This is suggested by our finding that the addition of an anti-M-CSF antibody to macrophage-UMR 106 cocultures resulted in pronounced inhibition of the expression of all phenotypic markers of osteoclast differentiation-that is, TRAP, $\mathrm{VNR}$, and lacunar resorption. M-CSF is produced by a large number of cell types, ${ }^{38}$ including fibroblasts, bone marrow stromal cells, osteoblasts, and activated macrophagesall of which may be found in the arthroplasty pseudomembrane or at the bone implant interface. $1,25(\mathrm{OH})_{2} \mathrm{D}_{3}$, the other humoral component we have identified as necessary for osteoclast formation from arthroplasty derived macrophages, is also likely to be present in increased amounts at the bone implant interface. Activated inflammatory foreign body macrophages are known to convert the comparatively inactive form of vitamin D, 25 hydroxyvitamin $\mathrm{D}_{3}$, to its most biologically active form, $1,25(\mathrm{OH})_{2} \mathrm{D}_{3}{ }^{39} 1,25(\mathrm{OH})_{2} \mathrm{D}_{3}$ is also known to promote monocyte-macrophage maturation and polykaryon formation. ${ }^{40} 41$

In aseptic loosening osteolysis occurs principally at the bone-implant interface where, in response to biomaterial wear particles continuously shed from prosthetic components, there is recruitment and constant turnover of foreign body macrophages in the arthroplasty pseudomembrane. In the context of this heavy inflammatory response, macrophageosteoclast differentiation may represent an important cellular mechanism whereby osteolysis is effected in aseptic loosening (fig 5). All the cellular and humoral elements that we have identified as necessary for this to occur - that is, macrophages, osteoblasts, $1,25(\mathrm{OH})_{2} \mathrm{D}_{3}$, and $\mathrm{M}-\mathrm{CSF}$ - can be found at the bone implant pseudomembrane interface. The in vitro model of osteoclast differentiation presented in this study, which uses human macrophages isolated from the periprosthetic tissues of patients suffering from aseptic loosening, should permit direct analysis of the cellular and humoral factors influencing this process.

This work was supported by the British Orthopaedic Association Wishbone Trust and the Wellcome Trust. We thank Mrs M Pearce for typing the manuscript.

1 Bullough PG, DiCarlo EF, Hansraj KK, Neves MC. Pathologic studies of total joint replacement. Orthop Clin North Am 1988;19:611-25.

2 Lennox DW, Schofield BW, McDonald DF, Riles LH. A histologic comparison of aseptic loosening of cemented, press-fit and biologic ingrowth prostheses. Clin Orthop
$1987 ; 225: 171-91$. 
3 Revell PA. Tissue reactions to joint prostheses and the products of wear and corrosion. In: Berry C, ed. Current trends in pathology. Berlin: Springer-Verlag, 1982: 73 - 101 Harris WH. Osteolysis and particle disease in hip replacements (a review). Acta Orthop Scand 1994;65:113-23.

5 Harris WH. The problem is osteolysis. Clin Orthop 1995;311:46-53.

6 Goodman SB, Chin RC. Prostaglandin E2 levels in the membrane surrounding bulk and particulate polymethylmethacrylate in the rabbit tibia: a preliminary study. Clin Orthop 1990;257:305-9.

7 Goodman SB, Chris RC, Chiou SS, Schurman DJ, Woolson ST, Masada MP. A clinical-pathological-biochemical study of the membrane surrounding loosened and non loosened total hip arthroplasties. Clin Orthop 1989; 244:182-7.

8 Murray DW, Rushton N. Macrophages stimulate bone resorption when they phagocytose particles. J Bone Joint resorption when they phas
Surg 1990;72B:988-92.

9 Jiranek WA, Machado M, Jasty M, Jervevar D Wolfe HJ, Goldring SR, et al. Production of cytokines around loosened cemented acetabular components. J Bone Joint loosened cemented aceto

10 Kim KJ, Rubash HE, Wilson SC, D'Antonio JA, McClain EJ. A histologic and biochemical comparison of the interface tissues in cementless and cemented hip prostheses. Clin Orthop 1993;287:142-52.

11 Quinn JM, Joyner C, Triffitt JT, Athanasou NA. PMMAinduced inflammatory macrophages resorb bone. J Bone Joint Surg 1992:74B:652-8.

12 Quinn JMW, Sabokbar A, NA Athanasou. Cells of the mononuclear phagocyte series differentiate into osteoclas-

13 Udagawa N, Takahashi N, Akatsu T, Tanaka H Sasaki T, Nishihara T, et al. Origin of osteoclasts: mature monocytes and macrophages are capable of differentiating into osteoand macrophages are capable of differentiating into osteoclasts under a suitable microenvironment prepared by bone marrow-derived stromal cells. Proc Natl Acad Sci
USA 1990;87:7260-4.

Fujika $190,87: 7260-4$.

Fujikawa Y, Quinn JMW, Sabokbar A, McGee JO'D, Athanasou NA. The human mononuclear osteoclast precursor circulates in the monocyte fraction. Endocrinology 1996 139:4058-60

15 Boyde A, Ali NN, Jones SJ. Resorption of dentine by isolated osteoclasts in vitro. Br Dent J 1984;156:216-20

16 Chambers TJ, Horton MA. Failure of cells of the mononuclear phagocyte series to resorb bone. Calcif Tissue Int 1984;36:556-68.

17 Pandey R, Quinn J, Joyner C, Murray DW, Triffitt JT, Athanasou NA. Arthroplasty implant biomaterial-associated macrophages differentiate into lacunar bone-resorbin cells. Ann Rheum Dis 1996;55:388-95.

18 Tanaka S, Takahashi N, Udagawa N, Tamura T, Akatsu T, Stanley ER, et al. Macrophage colony stimulating factor is indispensable for both proliferation and differentiation of osteoclast progenitors. J Clin Invest 1993;91:257-63.

19 Partridge N, Alcorn D, Michelangeli V, Kemp E, Ryan G Martin TJ. Functional properties of hormonal responsive Martin TJ. Functional properties of hormonal responsive
cultured normal and malignant rat osteoblastic cells. cultured normal and maligna

20 Minkin C. Bone acid phosphatase: tartrate-resistant acid phosphatase as a marker of osteoclast function. Calcif Tissue Int 1982;34:285-90

21 Horton MA, Lewis D, McNulty K, Pringle JAS, Chambers TJ. Monoclonal antibodies to osteoclastomas (giant cell bone tumours): definition of osteoclast specific cellular antigens. Cancer Res 1985;45:5663-9.

22 Athanasou NA, Quinn J. Immunophenotypic differences between osteoclasts and macrophage polykaryons: immunohistological distinction and implications for osteoclast ontogeny and function. J Clin Pathol 1990;43:997-1004.
23 Schlossman SF, Boumsell L, Gilks W, Harlan J, Kishimoto $\mathrm{T}$, Morimoto C, et al. Leucocyte typing V- White cell differentiation antigens. Proceedings of the 5th international workshop and conference held in Boston, USA. Vol 1, Oxford: Oxford University Press, 1995.

24 Amstutz HC, Campbell P, Kossovsky N, Clarke IC. Mechanisms and clinical significance of wear debris-induced osteolysis. Clin Orthop 1992;276:7-18.

25 Horowitz SM, Purdon MA. Mechanisms of cellular recruitment in aseptic loosening of prosthetic joint implants. Calcif Tissue Int 1995;57:301-5.

26 Malcolm AJ. The pathology of long-standing cemented total hip replacement in Charnley's cases. J Bone Joint Surg 1988;70B:153-6.

27 Santavirta S, Hoikka V, Eskola A, Kontinnen Y, Paavilainen $\mathrm{T}$, Tallroth V. Aggressive granulomatous lesions in cementless total hip arthroplasty. J Bone Joint Surg 1990a; 72(B): $980-4$.

28 Santavirta S, Konttinen TY, Bergroth V, Eskola A, Tallroth $\mathrm{K}$, Lindholm TS. Aggressive granulomatous lesions associated with hip arthroplasty: Immunopathological studies. J Bone Joint Surg 1990b;72(A):252-8.

29 Fujikawa Y, Sabokbar A, Neale S, Athanasou NA. Human osteoclast formation and bone resorption by monocytes and synovial macrophages in rheumatoid arthritis. Ann Rheum Dis 1996;55;816-22.

30 Athanasou NA, Quinn J, Horton MA, McGee JO'D. New sites of cellular vitronectin receptor immunoreactivity detected with osteoclast-reacting monoclonal antibodies 13C2 and 23C6. Bone and Mineral 1990;8:7-22.

31 Athanasou NA, Quinn J, Bulstrode CJK. Resorption of bone by inflammatory cells derived from the joint capsule of hip arthroplasties. J Bone Joint Surg 1992;74B:57-62.

32 Kadoya Y, Al-Saffar N, Kobayashi A, Revell PA. The expression of osteoclast markers on foreign body giant expression of osteoclast markers on for
cells. Bone and Mineral 1994;27:85-96.

33 Takahashi N, Udagawa N, Tanaka S, Murakanni H, Owan I, Tamura $\mathrm{T}$, et al. Postmitotic osteoclast precursors are mononuclear cells which express macrophage-associated phenotypes. Dev Biol 1994;163:212-21.

34 Takahashi N, Yamana H, Yoshiki S, Roodman GD, Mundy GR, Jones SJ, et al. Osteoclast-like cell formation and its regulation by osteotropic hormones in mouse bone
marrow cultures. Endocrinology 1988;122:1373-82.

35 Quinn JMW, McGee JO'D, Athanasou NA. Cellular and hormonal factors influencing monocyte differentiation to osteoclastic bone resorbing cells. Endocrinology 1994; 134:2416-23

36 Felix R, Cecchini MG, Fleisch H. Macrophage colony stimulating factor restores in vivo bone resorption in the $o p / o p$ osteopetrotic mouse. Endocrinology 1990; 127:2592-4.

37 Yoshida H, Hayashi S-I, Kunisada T, Ogawa M, Nishikawa $\mathrm{S}$, Okamura $\mathrm{H}$, et al. The murine mutation osteopetrosis is $\mathrm{S}$, Okamura $\mathrm{H}$, et al. The murine mutation osteopetrosis is
in the coding region of the macrophage colony stimulating in the coding region of the macrophage

38 Roth P, Stanley ER. The biology of CSF-1 and its receptor. Curr Top Microbiol Immunol 1992;181:141-67.

39 Rigby WFC. The immunobiology of vitamin D. Immunol Today 1988;9:54-8.

40 Suda T, Miyaura C, Abe E, Kuroki T. Modulation of cell differentiation, immune responses and tumour promotion research. Vol 4. Amsterdam: Elsevier BV, 1986: 1- 47 .

41 Kreutz M, Andreesen R. Induction of human monocyte to macrophage maturation in vitro by 1,25 dihydroxyvitamin $\mathrm{D}_{3}$. Blood 1990;12:2457-61. 